\title{
Factors associated with occurrence of salmonellosis among children living in Mukuru slum, an urban informal settlement in Kenya
}

Cecilia Mbae ${ }^{1 *}$, Moses Mwangi $^{2}$, Naomi Gitau', Tabitha Irungu', Fidelis Muendo², Zilla Wakio ${ }^{1}$, Ruth Wambui ${ }^{1}$, Susan Kavai ${ }^{1}$, Robert Onsare', Celestine Wairimu', Ronald Ngetich'1 , Frida Njeru', Sandra Van Puyvelde ${ }^{3,4,5}$, John Clemens $^{6}$, Gordon Dougan ${ }^{3}$ and Samuel Kariuki ${ }^{1,7}$

\begin{abstract}
Background: In Kenya, typhoid fever and invasive non-typhoidal salmonellosis present a huge burden of disease, especially in poor-resource settings where clean water supply and sanitation conditions are inadequate. The epidemiology of both diseases is poorly understood in terms of severity and risk factors. The aim of the study was to determine the disease burden and spatial distribution of salmonellosis, as well as socioeconomic and environmental risk factors for these infections, in a large informal settlement near the city of Nairobi, from 2013 to 2017.

Methods: Initially, a house-to-house baseline census of 150,000 population in Mukuru informal settlement was carried out and relevant socioeconomic, demographic, and healthcare utilization information was collected using structured questionnaires. Salmonella bacteria were cultured from the blood and faeces of children $<16$ years of age who reported at three outpatient facilities with fever alone or fever and diarrhea. Tests of association between specific Salmonella serotypes and risk factors were conducted using Pearson Chi-Square $\left(x^{2}\right)$ test.

Results: A total of 16,236 children were recruited into the study. The prevalence of bloodstream infections by NonTyphoidal Salmonella (NTS), consisting of Salmonella Typhimurium/ Enteriditis, was 1.3\%; Salmonella Typhi was 1.4\%, and this was highest among children $<16$ years of age. Occurrence of Salmonella Typhimurium/ Enteriditis was not significantly associated with rearing any domestic animals. Rearing chicken was significantly associated with high prevalence of S. Typhi (2.1\%; $p=0.011)$. The proportion of children infected with Salmonella Typhimurium/ Enteriditis was significantly higher in households that used water pots as water storage containers compared to using water directly from the tap (0.6\%). Use of pit latrines and open defecation were significant risk factors for $S$. Typhi infection $(1.6 \% ; p=0.048)$. The proportion of Salmonella Typhimurium/ Enteriditis among children eating street food 4 or more times per week was higher compared to 1 to 2 times/week on average $(1.1 \% ; p=0.032)$.

(Continued on next page)
\end{abstract}

\footnotetext{
* Correspondence: cmkathure@gmail.com; cmbae@kemri.org

${ }^{1}$ Centre for Microbiology Research, Kenya Medical Research Institute, Off Mbagathi Road, PO Box 54840-00200, Nairobi, Kenya

Full list of author information is available at the end of the article
}

(c) The Author(s). 2020 Open Access This article is licensed under a Creative Commons Attribution 4.0 International License, which permits use, sharing, adaptation, distribution and reproduction in any medium or format, as long as you give appropriate credit to the original author(s) and the source, provide a link to the Creative Commons licence, and indicate if changes were made. The images or other third party material in this article are included in the article's Creative Commons licence, unless indicated otherwise in a credit line to the material. If material is not included in the article's Creative Commons licence and your intended use is not permitted by statutory regulation or exceeds the permitted use, you will need to obtain permission directly from the copyright holder. To view a copy of this licence, visit http://creativecommons.org/licenses/by/4.0/. The Creative Commons Public Domain Dedication waiver (http://creativecommons.org/publicdomain/zero/1.0/) applies to the data made available in this article, unless otherwise stated in a credit line to the data. 
(Continued from previous page)

Conclusion: Typhoidal and NTS are important causes of illness in children in Mukuru informal settlement, especially among children less than 16 years of age. Improving Water, Sanitation and Hygiene (WASH) including boiling water, breastfeeding, hand washing practices, and avoiding animal contact in domestic settings could contribute to reducing the risk of transmission of Salmonella disease from contaminated environments.

Keywords: Invasive salmonellosis; children, Socioecomic, Environmental, Risk factors, Informal settlement, Nairobi, Kenya

\section{Background}

In sub-Saharan Africa (SSA) non-typhoidal Salmonella (NTS) is a major cause of invasive bacterial infections in infants and young children, the elderly, immunocompromised and the malnourished [1-6]. Invasive NTS disease is caused mainly by Salmonella enterica subspecies enterica serovars Typhimurium and Enteritidis [6-9]. Multi-drug resistant (MDR) iNTS is common in resourcepoor settings in Kenya [10], and in other parts of SSA [11-16] posing a major challenge to treatment and management options available. In studies on NTS in Kenya Tabu et al., (2012) documented crude incidence of 568/ 100,000 person-years of observation (pyo) in a rural site near Kisumu (Western Kenya) and 51/100,000 pyo in an urban informal settlement, Kibera, which is one of the major informal settlements in Nairobi. However, true rates in both sites were thought to be underestimated by 4-8 fold due to insensitivity of blood cultures (55-60\%) to detect bacteremic infections.

Typhoid fever, caused by $S$. Typhi is also endemic in SSA, partly because the supply of clean drinking water and sanitation have not kept pace with the rapid population growth [17]. Typhoid is now estimated to have an average annual incidence of $263 / 100,000$ pyo (95\% CI: 199-347) in all age groups in Kenya [18] and causes more illness among older children compared to NTS [6]. These rates are very similar to what has been documented in slums in Pakistan [19], India [20, 21] and Bangladesh [22]. The MDR-associated S. Typhi H58 clade is now widely disseminated in East Africa [8, 23-26]. In Kenya, MDR S. Typhi H58 has been associated with sporadic outbreaks involving adults and school-age children living within in resource-poor settings [25]. Unlike iNTS, HIV is not regarded as a major risk factor for typhoid fever [10].

In the informal settlements around Nairobi, epidemiology of typhoid and iNTS disease, transmission dynamics, risk factors and, the circulating serotypes and genotypes are not well understood. It is therefore important to carry out detailed surveillance to obtain data on temporal changes of Salmonella serotype diversity, risk factors and variations in their antimicrobial susceptibility profiles, which are crucial for informing clinical care, updating treatment guidelines, and guiding public health interventions.
More than 34\% of Kenyans live in urban areas, with more than $50 \%$ living in Informal Settlements that constitute only $5 \%$ of the residential area [27]. The informal settlements have limited access to clean water, sanitation facilities, solid-waste management, drainage, and electricity [28]. These factors likely contribute to a high incidence of diarrheal diseases and mortality among children [29, 30].

A major challenge in addressing the issues of managing both NTS and typhoid in our settings is emerging resistance to most commonly used antimicrobials, and now to even reserve antibiotics $[6,8]$. For instance, ESBL producing $S$. Typhimurium and $S$. Typhi with reduced susceptibility to fluoroquinolones pose a huge challenge in management of severe salmonellosis in Kenya.

The aim of this study was to determine the incidence, spatial distribution, socioeconomic and environmental risk factors for Salmonella infections in Mukuru informal settlement, one of the largest sprawling informal settlement $20 \mathrm{~km}$ east of Nairobi. In this paper, we report on a 5-year study of population-based surveillance for iNTS disease, typhoid fever, and NTS diarrhea, in children under 16 years of age.

\section{Methods}

\section{Mapping Mukuru informal settlement site}

Mukuru informal settlement is located $20 \mathrm{~km}$ east of Nairobi city, with a population of around 700,000 people [31] and is divided into eight villages; Mukuru LungaLunga, Mukuru Sinai, Mukuru kwa Reuben, Mukuru kwa Njenga, Mukuru Kayaba, Kosovo and Mukuru North. Our study was carried out in two of the villages, Mukuru kwa Njenga and Mukuru kwa Ruben, which have a population of approximately 150,000 . In the study area, families live in corrugated iron huts measuring ca. $10 \mathrm{ft}$. x $10 \mathrm{ft}$, and large families ( $4-8$ members) are crammed into this tiny space. During the rainy season storm drainage and sewer water runs around these shelters. The overcrowding and the lack of proper sanitary facilities likely contribute to the rapid spread of enteric infections. The residents obtain water from common watering points supplied by the City Council, each serving close to 1500 residents. In addition, several vendors hawk this water to residents.

A house-to-house baseline census was carried out and relevant socioeconomic, demographic, and healthcare 
utilization data was collected. Name and age of each member in the family and other members in the household was recorded so as to give the target list in the area for subjects. The census was preceded by an intensive campaign to publicize the study.

High resolution satellite imagery technology was used to create Household-level geographic information system (GIS) database. An image was acquired from Google Earth to create the map of structures/buildings of the study area as the first step of creating the GIS database. The satellite images were enhanced using image processing software before houses/buildings were digitized. GPS was used to capture data at several identifiable points on the images that would be used as ground control points (GCPs). The images were geometrically rectified to a known coordinate system, Universal Transverse Mercator (UTM) 37S, on the basis of a number of GCPs. After geo-referencing the images were resampled, and converted into TIFF files in ArcGIS10x software [32].

Considering the dynamic nature of the population sizes in slum areas, we fused use of high resolution satellite images to delineate houses, used local boundaries to associate the houses by roof, and ground truthing by way of household survey to geo-locate the population [33, 34].

\section{Block identification, numbering and hard copy labeling}

Mukuru kwa Ruben was divided into nine zones while Mukuru Kwa Njenga was divided into eight zones for purposes of Digitization and grouping blocks into individual zones (Table 1). The base map data used was high resolution Orthophoto aerial photographs in WGS84 Zone 37S Projected UTM Coordinates and analysed using Arc Map version 10.1. Total ground area of the study was 324.22 ha. The zone with the biggest area was Riara Zone with 51.67 ha while the smallest area was Bins Zone with 4.08 ha.

All the households, zones, roads and the outlining boundary of the region were digitized with each forming a shape file for the entire study area (Fig. 1). A high resolution hard copy A0 map with background orthophotos and zone boundary was printed for both Mukuru Kwa Ruben and Njenga regions. This facilitated fast labeling of the blocks where block numbers were labeled per zone to allow for the household census to start (Table 1). Zone 3a and $4 \mathrm{a}$ were the only ones labeled whereas zones 1a and 2a were excluded from the study area as they were of urban residential settlements. The household units as viewed from the printed aerial photos were numbered so as to facilitate the survey process which was to be carried out. The numbers on the map were later synchronized with the field Identity Numbers corresponding to the digitized households/plots so as to match the map, survey and the database.
Table 1 Mukuru villages Zones, area and number of Blocks per Zone

\begin{tabular}{|c|c|c|c|}
\hline Name & Zone No & Area $(\mathrm{Ha})$ & No. of Blocks Labeled \\
\hline \multicolumn{4}{|l|}{ Mukuru Kwa Ruben Zones } \\
\hline Bins Zone & 1 & 4.08 & 406 \\
\hline Mombasa Zone & 2 & 5.97 & 691 \\
\hline Feed the Children Zone & 3 & 5.84 & 507 \\
\hline Gatoto Zone & 4 & 6.95 & 551 \\
\hline Rurii Zone & 5 & 23.21 & 1003 \\
\hline Kosovo Zone & 6 & 13.09 & 775 \\
\hline Falcon Zone & 7 & 13.86 & 1026 \\
\hline Railway Zone & 8 & 21.85 & 1425 \\
\hline Simba Cool Zone & 9 & 18.62 & 675 \\
\hline \multicolumn{4}{|l|}{ Mukuru Kwa Njenga Zones } \\
\hline Riara Zone & $1 a$ & 51.67 & - \\
\hline MCC Zone & $2 a$ & 27.8 & - \\
\hline Motomoto Zone & $3 a$ & 14.28 & 876 \\
\hline Sisal Zone & $4 a$ & 38.13 & 2881 \\
\hline Vietynam Zone & $5 a$ & 30.43 & 1409 \\
\hline 48 Zone & $6 a$ & 25 & 1234 \\
\hline Milimani Zone & $7 a$ & 9.28 & 814 \\
\hline Wape Wape Zone & $8 a$ & 14.16 & 847 \\
\hline
\end{tabular}

\section{Surveillance for salmonella disease}

Patients were recruited from the three health care facilities serving the population, including Medical Missionaries of Mary, Reuben Centre and City council clinic in Embakasi. Inclusion criteria for cases included; children $<16$ years of age on the date of presentation who reside within Mukuru informal settlements, they presented with a subjective history of at least 3 days of fever and with axillary temperature of at least $38^{\circ} \mathrm{C}$ or had history of fever of any duration with an axillary temperature of at least $39^{\circ} \mathrm{C}$ and/or reported three or more loose or liquid stools in the $24 \mathrm{~h}$ before presentation, or one or more loose or liquid stool with visible blood. Eligible patients whose guardians provided a written informed consent had detailed history and physical examination recorded on a structured data form. Febrile patients had blood and stool (either whole stool or rectal swab) samples taken for culture and antibiotic susceptibility testing. All patients had blood taken for evaluation for malaria, HIV, and presence of sickle cell trait/disease. A transmittal form was used to track movement of samples from clinic to laboratory. A study log was kept at each clinic site, noting all potentially eligible patients, their presenting symptoms, whether or not they participated, reasons for non-participation, and whether blood specimens for culture, malaria smear, haemoglobin 


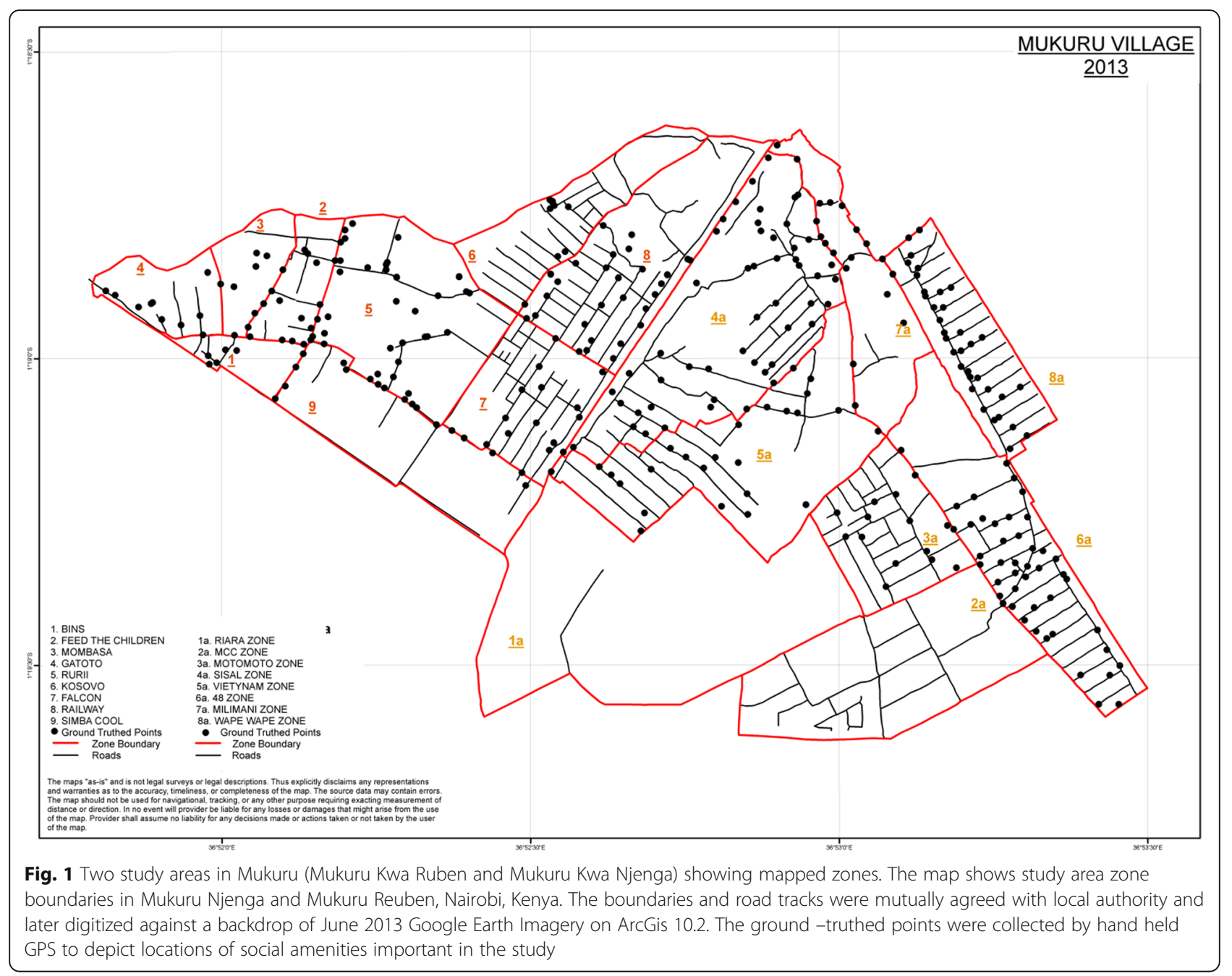

electrophoresis, and HIV testing and a faecal specimen for culture were collected and tested.

A total of 16,236 patients were recruited into the study. From eligible patients, stool specimen was collected in sterile sampling cups, part of the specimen was aliquoted using sterile cotton swabs in Cary Blair Transport Medium (Oxoid Ltd., Basingstoke, UK). The samples were then transferred to the laboratory at the Centre for Microbiology Research (KEMRI) within $4 \mathrm{~h}$. A structured questionnaire was used to elucidate the following information from each diarrhea case and healthy control after the stool samples were collected: clinical manifestations (e.g. vomiting, fever, and/or dehydration), demographic data (age, sex, and residence), and types of stool samples (watery, mucous, or bloody, or other form). For blood culture $1-3 \mathrm{ml}$ for children $<5$ years of age and $5-10 \mathrm{ml}$ for $5-16$ years of age was collected in syringe, placed into Tryptic Soy Broth (TSB) media in Bactec bottles, and transported daily to and analyzed at the KEMRI laboratory.

\section{Laboratory analysis} Blood for culture

Blood cultures were incubated at $37^{\circ} \mathrm{C}$ in a computerized BACTEC $^{\mathrm{m}} 9050$ Blood Culture System (BD, Franklin Lakes, New Jersey, USA), and subcultured after $24 \mathrm{~h}$ onto blood, chocolate and MacConkey agar plates. The blood cultures were subsequently observed for a further 7 days for signs of bacterial growth (auto-detection). A final subculture was performed for all blood cultures on the 8th day regardless of the state of bacterial growth. From the subcultures, bacterial isolates were identified using biochemical tests on API20E strips (API System, Montalieu Vercieu, France) and further typed by species-specific serological tests.

\section{Stool cultures}

The rectal swab or loopful of the stool specimen was transported to KEMRI laboratory and initially cultured on selenite F (Oxoid, Basingstoke, UK) broth aerobically at $37^{\circ} \mathrm{C}$ overnight. Broth cultures were then subcultured 
Table 2 Distribution of selected demographic characteristics

\begin{tabular}{lll}
\hline Variables & $N=16,236$ & $\%$ \\
\hline Gender of the child & 8296 & 51.1 \\
Male & 7940 & 48.9 \\
Female & & \\
Age of the child & 6408 & 39.5 \\
0-2 years & 3807 & 23.5 \\
3-4 years & 1980 & 12.2 \\
5-6years & 1339 & 8.3 \\
7-8 years & 2694 & 16.6 \\
Over 8years & 8 & \\
Missing & & \\
\hline
\end{tabular}

on MacConkey agar and Salmonella-Shigella agar (Oxoid) and incubated at $37^{\circ} \mathrm{C}$ overnight. To identify suspect Salmonella bacteria, non-lactose fermenting colonies were biochemically tested using triple sugar iron (TSI) slants. From the subcultures, bacterial isolates were identified using biochemical tests on API20E strips and further typed by species-specific serological tests (Remel, Thermo Fisher Scientific, MA, USA).

Antimicrobial susceptibility testing Antimicrobial susceptibility testing was performed using the disk diffusion technique for all commonly used antimicrobials in Kenya on Mueller-Hinton agar (Oxoid, Basingstoke, UK). Antimicrobial agents tested included; ampicillin $10 \mu \mathrm{g}$, tetracycline $30 \mu \mathrm{g}$, gentamicin $10 \mu \mathrm{g}$, trimethoprim $5 \mu \mathrm{g}$, sulphamethoxazole $100 \mu \mathrm{g}$, chloramphenicol $30 \mu \mathrm{g}$, co-amoxiclav 20:10 $\mu \mathrm{g}$, cefuroxime $30 \mu \mathrm{g}$, ceftazidime $30 \mu \mathrm{g}$, ceftriaxone $30 \mu \mathrm{g}$, cefotaxime $30 \mu \mathrm{g}$, ciprofloxacin $5 \mu \mathrm{g}$ and nalidixic acid $10 \mu \mathrm{g}$. Determination of the minimum inhibitory concentrations of the antimicrobials was performed using the E-test strips (AB BIODISK, Solna, Sweden). Results were interpreted according to the guidelines provided by the Clinical and Laboratory Standards Institute (CLSI) (2017).

\section{Patient information and care}

After laboratory analysis of the samples, results were taken back to the attending clinician for patient management. Those that were found to be positive for salmonella infection were contacted on telephone, and asked to report to the clinic, where the results were communicated to them. The clinician then provided a drug prescription based on the antimicrobial susceptibility test results. The patient/guardian was given details on the importance of taking and completing the drug dose, and health information on the disease, and how to prevent future infections. All patients were given water treatment tablets after the health education. The patient/ guardian was then handed over to a community health worker $(\mathrm{CHW})$, who would follow the patient to their homes and fill in a questionnaire on socio-demographic characteristics of the household and assess other environmental risk factors for enteric diseases. The questionnaire collected information including; demographic and socioeconomic features of the households: age and sex of all residents, household size, income, ownership of luxury items, and education, the source of water used for drinking and washing, hand washing location, presence of hand soap at the hand washing location, use of refuse containers, presence of visible stool in the yard or home, types of water storage containers used in the home, site(s) and structure(s) used for defecation, household food preparation methods, out of household food exposures, antibiotic use during the 2 weeks prior to presentation of the case, and presence and number of different domesticated animals in the house. The $\mathrm{CHW}$ also followed up the patients to ensure that they have reported back to the clinic for stool culture re-testing after completion of the treatment.

Table 3 Salmonella disease in relation to selected demographic characteristics

\begin{tabular}{|c|c|c|c|c|c|c|c|}
\hline & \multicolumn{4}{|c|}{ Salmonella Typhimurium/Enteriditis } & \multicolumn{3}{|c|}{ Salmonella Typhi } \\
\hline & $\mathrm{N}$ & Pos (\%) & $O R^{a}\left(\left.95 \% C\right|^{b}\right)$ & $p$ value & Pos (\%) & $O R^{a}\left(\left.95 \% C\right|^{b}\right)$ & $p$ value \\
\hline \multicolumn{8}{|c|}{ Gender of the child } \\
\hline Male & 7861 & $1.40 \%$ & $0.93(0.71-1.21)$ & 0.57 & $1.80 \%$ & $1.49(1.15-1.95)$ & 0.003 \\
\hline Female & 7487 & $1.50 \%$ & Ref & & $1.20 \%$ & Ref & \\
\hline \multicolumn{8}{|c|}{ Age of the child } \\
\hline $0-2$ years & 5992 & $1.30 \%$ & Ref & & $1.10 \%$ & Ref & \\
\hline $3-4$ years & 3607 & $1.60 \%$ & $1.21(0.85-1.70)$ & 0.277 & $1.50 \%$ & $1.41(0.98-2.03)$ & 0.066 \\
\hline $5-6$ years & 1903 & $1.40 \%$ & $1.06(0.69-1.65)$ & 0.783 & $2.60 \%$ & $2.45(1.68-3.56)$ & $<0.001$ \\
\hline $7-8$ years & 1277 & $1.60 \%$ & $1.18(0.72-1.93)$ & 0.52 & $2.10 \%$ & $2.00(1.27-3.15)$ & 0.003 \\
\hline over 8 years & 2561 & $1.30 \%$ & $0.99(0.66-1.49)$ & 0.978 & $1.50 \%$ & $1.43(0.96-2.14)$ & 0.079 \\
\hline
\end{tabular}

${ }^{a} O R$ Odds Ratio. ${ }^{b} \mathrm{Cl}$ Confidence interval 
Table 4 Distribution of homesteads by specific domestic animal kept, water, hygiene, sanitation and source of food

\begin{tabular}{lll}
\hline Variables & $N=16$, & $\%$ \\
& 236 & \\
\hline Sheep & 451 & 2.8 \\
Cattle & 639 & 3.9 \\
Dogs & 1868 & 11.5 \\
Pigs & 980 & 6 \\
Cats & 3774 & 23.2 \\
Chicken & 2921 & 18 \\
Goats & 1018 & 6.3 \\
Other & 335 & 2.1 \\
Main source of drinking water in the house & & \\
Own tap & 1113 & 6.9 \\
Own well & 89 & 0.5 \\
Communal tap & 12,730 & 78.5 \\
Communal well/pump & 1938 & 12 \\
River/Spring/Rainwater & 52 & 0.3 \\
Other & 285 & 1.8 \\
Missing & 29 &
\end{tabular}

Existing contamination sources around the water $\quad \begin{array}{ll}12,129 & 75.2\end{array}$ source within $20 \mathrm{~m}$

e.g. open sewers, communal latrines/toilets

Types of water storage containers used in the home

$\begin{array}{lll}\text { Directly from tap } & 744 & 4.6 \\ \text { Water pot } & 6054 & 37.6 \\ \text { Pitcher } & 1809 & 11.2 \\ \text { Jerri can } & 6224 & 38.6 \\ \text { Other } & 1288 & 8 \\ \text { Missing } & 117 & \end{array}$

Water generally boiled before drinking

Always

Sometimes

Never

Don't know

Missing

Type of toilet used by the Household

Public toilet

Flush toilet

Pit latrine

Bush/river/canal

Don't know

Missing

Household members wash hands after defecation

Always

Sometimes

Never
$6025 \quad 40$

$2929 \quad 19.4$

$6069 \quad 40.3$

$46 \quad 0.3$

1109

$10,891 \quad 67.4$

$4529 \quad 28$

$661 \quad 4.1$

$72 \quad 0.4$

$15 \quad 0.1$

10

$13,211 \quad 81.7$

$2722 \quad 16.8$

$115 \quad 0.7$

Table 4 Distribution of homesteads by specific domestic animal kept, water, hygiene, sanitation and source of food (Continued)

\begin{tabular}{lll}
\hline Variables & $\begin{array}{l}N=16, \\
236\end{array}$ & \\
\hline Don't know & 118 & 0.7 \\
Missing & 70 & \\
Frequency of family eating street food & & \\
$\quad$ Never/rarely & 3787 & 23.6 \\
1 to 2 times/week & 6109 & 38 \\
3 to 5 times/week & 3922 & 24.4 \\
4 or more/week & 2242 & 14 \\
$\quad$ Missing & 176 & \\
Grow in backyard & 205 & 1.3 \\
Buy from shop & 8247 & 50.8 \\
Buy from neighbor & 1397 & 8.6 \\
Buy from our mobile vendor & 4519 & 27.8 \\
Buy from village market & 4104 & 25.3 \\
\hline
\end{tabular}

\section{Data analysis for risk factors}

Statistical analyses were performed using SPSS software version 25.0. Descriptive statistics were presented as counts and percentages. Tests of association between specific salmonellosis and risk factors were conducted using Pearson Chi-Square $\left(x^{2}\right)$ test. Odds ratio and their corresponding confidence interval $(95 \% \mathrm{CI})$ were used to measure the strength of association. The threshold for significance was set at 0.05 for all tests. All significant risk factors ( $p$-value $<0.05)$ were adjusted for confounders and risk modifiers using multivariable binary logistic regression and specifying backward conditional as the removal method. Reduced model showing adjusted odds ratio, their corresponding confidence intervals $(95 \% \mathrm{CI})$ and $p$-values were reported.

\section{Ethics approval and consent to participate}

Written informed consent to participate was obtained from the parents/guardians of the minors included in this study (minors were defined as anyone under the age of 16 years). Ethical approval was granted by the Scientific Ethics and Review Unit (SERU) of the Kenya Medical Research Institute (KEMRI) (SSC. No. 2076), and from the County Health Executive and Ministry of Health, Embakasi subcounty.

\section{Results}

Selected demographic characteristics and salmonella disease

A total of 16,236 children were recruited into the study. The prevalence of Salmonella Typhimurium/ Enteriditis from blood and stool of patients with fever was 1.3\% (CI: $1.1-1.5 \%$ ), while that of $S$. Typhi was $1.4 \%$ (CI: $1.2-$ $1.6 \%)$. There was a comparable male $(51.1 \%)$ to female 
(48.9\%) while most of the children (63.0\%) were aged less than 5 years, constituted by $39.5 \%$ aged 0 to 2 years and $23.5 \%$ aged 3 to 4 years. Table 2 presents the distribution of children in the study by selected demographic characteristics.

The occurrence of Salmonella Typhimurium/Enteriditis was not significantly associated with the selected demographic characteristics presented (Table 3). However, males were significantly associated with high prevalence of $S$. Typhi (1.8\%; OR = 1.49 (CI:1.15-1.95); $p=0.003)$ compared to females (1.2\%). A high proportion of infection with $S$. Typhi was observed among children aged 5-6 years $(2.6 \% ; \mathrm{OR}=2.45(\mathrm{CI}: 1.68-3.56) ; p<0.001)$ and $7-8$ years $(2.1 \%$; OR $=2.00(\mathrm{CI}: 1.27-3.15) ; p=0.003)$, compared to children aged $0-2$ years (1.1\%).

The influence of domestic animals on salmonella disease The most common animals included cats (23.2\%), chicken (18.0\%) and dogs (11.5\%), whereas other animals accounted for less than $10 \%$. Table 4 presents the distribution of homesteads by specific domestic animal kept, water, hygiene, sanitation and source of food. The majority of the households in the settlement use a communal tap (78.5\%), with $75.2 \%$ reporting the existence of contamination sources within 20 $\mathrm{m}$ of the water source. The most commonly used water storage containers in the home included Jerri cans $(38.6 \%)$ and water pots (37.6\%), with $40.6 \%$ of the households never boiled water before drinking. Most of the households (67.4\%) used public toilets while $28.0 \%$ used flushing toilets. The majority (81.7\%) of the households reported that they washed their hands after defecation.

The occurrence of Salmonella Typhimurium/Enteriditis was not significantly associated with rearing any domestic animal (Table 5). However, rearing chickens and goats was significantly associated with a higher prevalence of $S$. Typhi (2.1\%; OR $=1.75$ (CI:1.15-2.70); $p=0.011 ; \quad$ and $(2.5 \% ; \quad$ OR $=1.49 \quad(\mathrm{CI}: 1.15-2.00) ; \quad p=$ $0.011)$, respectively.

Table 5 Salmonella disease in relation to keeping domestic animals

\begin{tabular}{|c|c|c|c|c|c|c|c|}
\hline \multirow[t]{2}{*}{ Variables } & \multicolumn{4}{|c|}{ Salmonella Typhimurium/ Enteriditis } & \multicolumn{3}{|c|}{ Salmonella Typhi } \\
\hline & $\mathrm{N}$ & Pos (\%) & $\mathrm{OR}^{\mathrm{a}}(95 \% \mathrm{Cl})$ & $p$ value & Pos (\%) & $\left.\mathrm{OR}(95 \% \mathrm{eCl})^{\mathrm{b}}\right)$ & $p$ value \\
\hline \multicolumn{8}{|l|}{ Sheep } \\
\hline Not present & 14,931 & $1.40 \%$ & $0.99(0.44-2.24)$ & 0.983 & $1.50 \%$ & $1.05(0.47-2.38)$ & 0.893 \\
\hline Present & 417 & $1.40 \%$ & Ref & & $1.40 \%$ & Ref & \\
\hline \multicolumn{8}{|l|}{ Cattle } \\
\hline Not present & 14,755 & $1.40 \%$ & $1.22(0.57-2.6)$ & 0.606 & $1.50 \%$ & $0.81(0.44-1.49)$ & 0.495 \\
\hline Present & 593 & $1.20 \%$ & Ref & & $1.90 \%$ & Ref & \\
\hline \multicolumn{8}{|l|}{ Dogs } \\
\hline Not present & 13,582 & $1.40 \%$ & $0.96(0.64-1.46)$ & 0.864 & $1.50 \%$ & $0.78(0.54-1.14)$ & 0.202 \\
\hline Present & 1766 & $1.50 \%$ & Ref & & $1.90 \%$ & Ref & \\
\hline \multicolumn{8}{|l|}{ Pigs } \\
\hline Not present & 14,442 & $1.40 \%$ & $0.92(0.53-1.58)$ & 0.757 & $1.50 \%$ & $0.75(0.46-1.21)$ & 0.237 \\
\hline Present & 906 & $1.50 \%$ & Ref & & $2.00 \%$ & Ref & \\
\hline \multicolumn{8}{|l|}{ Cats } \\
\hline Not present & 11,773 & $1.50 \%$ & $1.28(0.92-1.8)$ & 0.148 & $1.50 \%$ & $0.93(0.69-1.27)$ & 0.672 \\
\hline Present & 3575 & $1.20 \%$ & Ref & & $1.60 \%$ & Ref & \\
\hline \multicolumn{8}{|l|}{ Chicken } \\
\hline Not present & 12,578 & $1.40 \%$ & $0.85(0.61-1.18)$ & 0.333 & $1.40 \%$ & Ref & \\
\hline Present & 2770 & $1.60 \%$ & Ref & & $2.10 \%$ & $1.75(1.15-2.70)$ & 0.011 \\
\hline \multicolumn{8}{|l|}{ Goats } \\
\hline Not present & 14,391 & $1.40 \%$ & $1.05(0.60-1.85)$ & 0.854 & $1.50 \%$ & Ref & \\
\hline Present & 957 & $1.40 \%$ & Ref & & $2.50 \%$ & $1.49(1.10-2.00)$ & 0.011 \\
\hline \multicolumn{8}{|l|}{ Other } \\
\hline Not present & 15,038 & $1.40 \%$ & $1.11(0.41-3.00)$ & 0.838 & $1.50 \%$ & $1.74(2.68-1.14)$ & 0.74 \\
\hline Present & 310 & $1.30 \%$ & Ref & & $1.30 \%$ & Ref & \\
\hline
\end{tabular}


The effect of water, hygiene and sanitation on occurrence of salmonella disease

The proportion of children infected with Salmonella Typhimurium/ Enteriditis was significantly higher in households that used water pots $(1.6 \%$; OR $=2.75(\mathrm{CI}$ : $1.01-7.51) ; p=0.0048)$ and Jerri cans (1.6\%; OR = $2.81(\mathrm{CI}: 1.03-7.66) ; p=0.044)$ to store water compared to using water directly from the tap (0.6\%) (Table 6). A similar trend was observed among households that use pit latrines (2.5\%; OR $=1.77(\mathrm{CI}: 1.01-3.08) ; p=0.045)$ compared to households using flush toilets (1.4\%). Similarly, the use of bush/river/canal $(5.6 \%$; OR $=4.93(\mathrm{CI}$ :

Table 6 Salmonella disease in relation to various predictors

\begin{tabular}{lll}
\hline $\begin{array}{l}\text { Predictors of Salmonella } \\
\text { Variables }\end{array}$ & $\begin{array}{l}\text { Typhimurium/Enteriditis } \\
\text { Frequency of family eating street food }\end{array}$ & $\boldsymbol{p}$-value \\
Never/rarely & $0.84(0.55-1.29)$ & 0.435 \\
1 to 2 times/week & $0.65(0.43-0.98)$ & $\mathbf{0 . 0 4 1}$ \\
3 to 5 times/week & $0.95(0.62-1.44)$ & 0.8 \\
4 to 6 more /week & Ref &
\end{tabular}

Types of water storage containers used in the home

$\begin{array}{lll}\text { Directly from tap } & \text { Ref } & \\ \text { Water pot } & 2.69(0.98-7.37) & 0.054 \\ \text { Pitcher } & 1.18(0.38-3.69) & 0.772 \\ \text { Jerri can } & 2.63(0.96-7.19) & 0.059 \\ \text { Other } & 2.13(0.71-6.41) & 0.178\end{array}$

Predictors of Salmonella Typhi

\begin{tabular}{lll}
$\begin{array}{l}\text { Variables } \\
\text { Gender of the child }\end{array}$ & $\mathbf{a O R}^{\mathbf{a}}\left(\mathbf{9 5} \% \mathrm{Cl}^{\mathbf{b}}\right)$ & $\boldsymbol{p}$ value \\
Male & $1.53(1.17-2.01)$ & $\mathbf{0 . 0 0 2}$ \\
$\begin{array}{l}\text { Female } \\
\text { Age of the child }\end{array}$ & \\
0-2 years & Ref & \\
3-4 years & $1.43(0.99-2.07)$ & 0.059 \\
5-6years & $2.49(1.70-3.65)$ & $<\mathbf{0 . 0 0 1}$ \\
7-8years & $2.08(1.31-3.28)$ & $\mathbf{0 . 0 0 2}$ \\
Over 8 years & $1.43(0.95-2.15)$ & 0.083 \\
Keeping chicken & & \\
Present & $1.33(0.95-2.15)$ & 0.071 \\
Not present & Ref & \\
Type of toilet used by the household & \\
Public toilet & $1.35(0.98-1.87)$ & 0.064 \\
Flush toilet & Ref & \\
Pit latrine & $1.53(0.81-2.90)$ & 0.193 \\
Bush/river/canal & $5.11(1.79-14.62)$ & $\mathbf{0 . 0 0 2}$ \\
Don't know & UD(N/A) & 1 \\
\hline
\end{tabular}

${ }^{a}$ OR Odds Ratio. ${ }^{b} \mathrm{Cl}$ Confidence interval N/A not applicable
$1.73-14.03) ; p=0.003)$ and pit latrines (1.6\%; $\mathrm{OR}=$ $1.37(\mathrm{CI}: 1.00-1.89) ; p=0.048)$ as toilets was associated with a higher proportion of $S$. Typhi infection among children compared to use of flush toilet (1.2\%). The proportion of children infected with $S$. Typhi was significantly higher amongst households whose members never wash hands after defecation $(4.5 \%$; OR $=3.18(\mathrm{CI}$ : $1.28-7.90) ; p=0.013)$ compared to households where they always practice hand washing (1.5\%).

\section{Household sources of food}

The proportion of Salmonella Typhimurium/Enteriditis was significantly higher among children raised in households whose frequency of eating street food was 4 to 6 or more times compared to 1 to 2 times/week (1.1\%; $\mathrm{OR}=0.64(\mathrm{CI}: 0.43-0.96) ; p=0.032)$. The occurrence of $S$. Typhi was not significantly associated with any specific source of food within the informal settlement (Table 7). A total of $38.4 \%$ of the families from the study area ate street food three or more times/week. Approximately half of these (50.8\%) bought food from the shop, with $27.8 \%$ buying from mobile vendors and $25.3 \%$ from a village market as shown in Table 7. A relatively small number of households grew vegetables in the backyard (1.3\%), with $8.6 \%$ buying from neighbours.

\section{Predictors of salmonella disease among children living in Mukuru informal settlement}

Factors identified by bivariate analysis showing significant association with specific Salmonella serotype include the frequency of family eating street food, types of water storage containers used, gender and age of the child, keeping chicken and type of toilet used by the household. Table 8 presents the predictors of Salmonellosis among children living in Mukuru informal settlement.

Adjusting for other factors, reduced frequency of family eating street food (1 to 2 times/week) was identified as a being protective against contracting Salmonella Typhimurium/Enteriditis $(\mathrm{aOR}=0.65$; CI:0.43-0.98; $p=$ $0.041)$. Additionally, using water pots $(\mathrm{aOR}=2.69$; $\mathrm{CI}$ : $0.98-7.37 ; p=0.054)$ and Jerri cans $(\mathrm{aOR}=2.63 ; \mathrm{CI}$ : $0.96-7.19 ; p=0.059)$ as water storage containers in the home potentially predicted infection with Salmonella Typhimurium/Enteriditis. Adjusting for other factors, male gender $(\mathrm{aOR}=1.53 ; \mathrm{CI}: 1.17-2.01 ; p=0.002)$, age $5-6$ years $(\mathrm{aOR}=2.49 ; \mathrm{CI}: 1.70-3.65 ; p<0.001)$, age $7-8$ years $(\mathrm{aOR}=2.08$; $\mathrm{CI}: 1.31-3.28 ; p=0.002)$ and defecating in the bush/river/canal $(\mathrm{aOR}=5.11$; 95\% CI:1.79$14.62 ; p=0.002)$ were predictive of contracting $S$. Typhi. Additionally, adjusting for other factors, age 3-4 years $(\mathrm{aOR}=1.43 ; \mathrm{CI}: 0.99-2.07 ; p=0.059)$, age 9 years and above $(\mathrm{aOR}=1.43 ; \mathrm{CI}: 0.95-2.15 ; p=0.083)$, keeping chicken $(\mathrm{aOR}=1.33$; $\mathrm{CI}$ : $0.95-2.15 ; p=0.071)$ and using 
Table 7 Salmonella disease in relation to source of food

\begin{tabular}{|c|c|c|c|c|c|c|c|}
\hline \multirow[t]{2}{*}{ Variables } & \multicolumn{4}{|c|}{ Salmonella Typhimurium/Enteriditis } & \multicolumn{3}{|c|}{ Salmonella Typhi } \\
\hline & $\bar{N}$ & Pos (\%) & $\mathrm{OR}^{\mathrm{a}}\left(95 \% C \mathrm{C}^{\mathrm{b}}\right)$ & $\overline{p \text { value }}$ & Pos (\%) & $\mathrm{OR}^{\mathrm{a}}\left(95 \% C \mathrm{I}^{\mathrm{b}}\right)$ & $p$ value \\
\hline \multicolumn{8}{|c|}{ Frequency of family eating street food } \\
\hline Never/rarely & 3594 & $1.50 \%$ & $0.83(0.54-1.27)$ & 0.394 & $1.50 \%$ & $1.03(0.66-1.62)$ & 0.899 \\
\hline 1 to 2 times/week & 5788 & $1.10 \%$ & $0.64(0.43-0.96)$ & 0.032 & $1.50 \%$ & $1.07(0.71-1.63)$ & 0.736 \\
\hline 3 to 5 times/week & 3707 & $1.70 \%$ & $0.95(0.63-1.43)$ & 0.788 & $1.60 \%$ & $1.11(0.71-1.73)$ & 0.636 \\
\hline 4 to 6 more /week & 2093 & $1.80 \%$ & Ref & & $1.40 \%$ & Ref & \\
\hline \multicolumn{8}{|l|}{ Growing in backyard } \\
\hline No & 15,153 & $1.40 \%$ & $0.69(0.25-1.87)$ & 0.462 & $1.50 \%$ & $0.48(0.22-1.08)$ & 0.08 \\
\hline Yes & 195 & $2.10 \%$ & Ref & & $3.10 \%$ & Ref & \\
\hline \multicolumn{8}{|l|}{ Buying from shop } \\
\hline No & 7468 & $1.50 \%$ & $1.17(0.90-1.53)$ & 0.251 & $1.40 \%$ & $0.91(0.71-1.178)$ & 0.478 \\
\hline Yes & 7880 & $1.30 \%$ & Ref & & $1.60 \%$ & Ref & \\
\hline \multicolumn{8}{|c|}{ Buying from neighbour } \\
\hline No & 14,021 & $1.40 \%$ & $1.00(0.62-1.60)$ & 0.987 & $1.50 \%$ & $0.82(0.54-1.27)$ & 0.367 \\
\hline Yes & 1327 & $1.40 \%$ & Ref & & $1.80 \%$ & Ref & \\
\hline \multicolumn{8}{|c|}{ Buying from mobile vendor } \\
\hline No & 11,109 & $1.40 \%$ & $0.83(0.62-1.10)$ & 0.196 & $1.60 \%$ & $1.29(0.95-1.79)$ & 0.094 \\
\hline Yes & 4239 & $1.60 \%$ & Ref & & $1.30 \%$ & Ref & \\
\hline \multicolumn{8}{|c|}{ Buying from village market } \\
\hline No & 11,552 & $1.50 \%$ & $1.21(0.87-1.67)$ & 0.259 & $1.50 \%$ & $0.99(0.74-1.33)$ & 0.955 \\
\hline Yes & 3796 & $1.20 \%$ & Ref & & $1.50 \%$ & Ref & \\
\hline
\end{tabular}

public toilets $(\mathrm{aOR}=1.35$; $\mathrm{CI}: 0.98-1.87 ; p=0.064)$ potentially predicted infection with $S$. Typhi.

\section{Discussion}

We conducted a hospital-based cross-sectional study among children aged $<16$ years in one of the major informal settlements of Nairobi, Kenya, in order to determine the prevalence and risk factors associated with salmonellae infection. The prevalence of the major NTS serotypes (Salmonella Typhimurium and S. Enteriditis) in the population was $1.3 \%$ (95\% CI: $1.1-1.5 \%$ ), while that of $S$. Typhi was $1.4 \%$ (95\% CI: $1.2-1.6 \%$ ). The male gender, age and defecating in the bush/river/canal were predictive of contracting $S$. Typhi, while keeping chicken and using public toilet was associated with NTS diarrhoeal illness. In addition, socioeconomic status of a family was a major risk factor for life-threatening iNTS disease. It is important to note that Nairobi's informal settlements where these studies were performed are characterized by dense population, poor sanitation, and unreliable water supply. These are ingredients that create an environment conducive for rapid spread of enteric infections and other sanitation-related pathogens through contaminated food and water [28].
Previous studies from countries such as Qatar [35] and Turkey [36] indicated no statistically significant difference in typhoid prevalence between boys and girls. However, other investigations from Bagladesh [37] found similar findings to ours, with statistically significant higher typhoid infection in boys compared with girls. This perhaps reflects greater exposure of males to contaminated food and water outside the home probably due to their play habits within the slum area where the level of sanitation is low. In our study, higher proportions of infection with $S$. Typhi was observed among children aged 5-6years and 7-8 years whereas lower proportions were observed among children aged $0-2$ years. This could be attributed to the fact that schoolgoing children spend significantly more time playing outside in and around open wastewater trenches. Indirect environmental or fly-based transmission may also have contributed to enhanced disease spread [38, 39]. This is consistent with the finding that infections were higher among children from households that use pit latrine and those who use bush/river/canal as a toilet compared to households using flush toilet. The pit latrines are shared among many households hence increasing the risk of infection through contaminated surfaces in the facility. 
Table 8 Predictors of salmonella disease among children

\begin{tabular}{|c|c|c|}
\hline \multicolumn{3}{|c|}{ Predictors of Salmonella Typhimurium/Enteriditis } \\
\hline Variables & $\mathrm{aOR}^{\mathrm{a}}\left(95 \% \mathrm{Cl}^{\mathrm{b}}\right)$ & $p$ value \\
\hline \multicolumn{3}{|c|}{ Frequency of family eating street food } \\
\hline Never/rarely & $0.84(0.55-1.29)$ & 0.435 \\
\hline 1 to 2 times/week & $0.65(0.43-0.98)$ & 0.041 \\
\hline 3 to 5 times/week & $0.95(0.62-1.44)$ & 0.800 \\
\hline 4 to 6 more /week & Ref & \\
\hline
\end{tabular}

Types of water storage containers used in the home

$\begin{array}{lll}\text { Directly from tap } & \text { Ref } & \\ \text { Water pot } & 2.69(0.98-7.37) & 0.054 \\ \text { Pitcher } & 1.18(0.38-3.69) & 0.772 \\ \text { Jerri can } & 2.63(0.96-7.19) & 0.059 \\ \text { Other } & 2.13(0.71-6.41) & 0.178\end{array}$

Predictors of Salmonella Typhi

\begin{tabular}{|c|c|c|}
\hline Variables & $\mathrm{aOR}^{\mathrm{a}}\left(95 \% \mathrm{Cl}^{\mathrm{b}}\right)$ & $p$ value \\
\hline \multicolumn{3}{|c|}{ Gender of the child } \\
\hline Male & $1.53(1.17-2.01)$ & 0.002 \\
\hline Female & Ref & \\
\hline \multicolumn{3}{|l|}{ Age of the child } \\
\hline $0-2$ years & Ref & \\
\hline $3-4$ years & $1.43(0.99-2.07)$ & 0.059 \\
\hline $5-6$ years & $2.49(1.70-3.65)$ & $<0.001$ \\
\hline $7-8$ years & $2.08(1.31-3.28)$ & 0.002 \\
\hline Over 8 years & $1.43(0.95-2.15)$ & 0.083 \\
\hline \multicolumn{3}{|l|}{ Keeping chicken } \\
\hline Present & $1.33(0.95-2.15)$ & 0.071 \\
\hline Not present & Ref & \\
\hline \multicolumn{3}{|c|}{ Type of toilet used by the household } \\
\hline Public toilet & $1.35(0.98-1.87)$ & 0.064 \\
\hline Flush toilet & Ref & \\
\hline Pit latrine & $1.53(0.81-2.90)$ & 0.193 \\
\hline Bush/river/canal & $5.11(1.79-14.62)$ & 0.002 \\
\hline Don't know & UD(N/A) & 1.000 \\
\hline
\end{tabular}

The occurrence of iNTS disease was not significantly associated with rearing any domestic animal. Previously it was hypothesized that NTS transmission may be person-to-person rather than through zoonotic reservoirs of NTS bacteria $[13,40]$. Rearing chicken was associated with high prevalence of $S$. Typhi $(2.1 \%$; OR $=1.75$ (CI:1.15-2.70); $p=0.011)$ compared to not rearing chicken (1.4\%). Similarly, rearing goats was significantly associated with high prevalence of $S$. Typhi (2.5\%; OR = 1.49 (CI:1.15-2.00); $p=0.011$ ) compared to not rearing goats. While livestock may not play a role in direct transmission of typhoid, as $S$. Typhi is a human-adapted pathogen, it is likely that keeping livestock is a confounder and may be associated with poor unhygienic conditions in the home.

The proportion of children infected with NTS was significantly higher in households that used water pots as water storage containers compared to those using water directly from the tap. In the informal settlements, water shortage is common and therefore the practice of storing water in pots and plastic containers at home for days before consumption is common. The proportion of children infected with $S$. Typhi was significantly higher among household whose members never washed hands after defecation compared to households where they always practiced hand washing. It is important that people, especially caregivers should always be encouraged to wash their hands after use of a toilet and before feeding, as contamination of hands with fecal matter leads to contamination of surfaces and foods [41].

Globally, it is estimated that Salmonella spp. are the cause of over 90 million of diarrhea-associated diseases annually, with $85 \%$ of those cases being linked to foodborne sources [42]. Multiple investigations have demonstrated that a considerable proportion of Salmonella transmission occurs through contamination along the food chain such as from slaughter of livestock, vegetable and foodcrops harvest to household food preparation $[43,44]$. We found that over one-third of the families (38.4\%) ate street food three or more times/week, and approximately half of the households bought their food ingredients and vegetables from the shops, with $27.8 \%$ buying from mobile vendors and $25.3 \%$ from the village market. Consequently, the proportion of salmonella disease was significantly higher among children raised in households whose frequency of eating street food was high. This is corroborated by previous studies in Africa and Asia, which showed that crowded living conditions and poor sanitation were significantly associated with outbreaks of typhoid fever [45-48].

\section{Conclusion}

This study observed that typhoidal and NTS are important causes of illness in children in Mukuru informal settlements, one of the largest informal settlements in the outskirts of Nairobi city. The male gender, age and defecating in the bush/river/canal and using public toilet were important risk factors associated with these diarrhoeal illnesses. The improvement of WASH infrastructure and practices, including boiling water, breastfeeding, hand washing practices, and avoiding animal contact in domestic setting could contribute to reducing the risk of transmission of salmonella disease from contaminated environments common in such settings. 


\section{Abbreviations}

SSA: Sub-Saharan Africa; NTS: Non- typhoidal Salmonella; iNTS: Invasive Nontyphoidal Salmonella; HIV: Human Immunodeficiency Sydrome; MDR: Multdrug resistant; Pyo: Person-years of observation; NTS D: Non-typhoidal Salmonella diarrhea; GIS: Geographic Information System; GPS: Global positioning system \GCPs- Ground Control Points; UTM: Universal Transverse Mercator; KEMRI: Kenya Medical Research Institute; CLSI: Clinical and Laboratory Standards Institute; CHW: Community Health Worker; SERU: Scientific Ethics and Review Unit; OR: Odds Ratio; Cl: Confidence intervals

\section{Acknowledgements}

The authors thank the Director General, KEMRI for support in publishing these data. We acknowledge the field and laboratory staff of the Mukuru kwa Njenga Invasive Salmonella Disease Surveillance Project for their contribution in data collection and laboratory analysis.

\section{Authors' contributions}

CM, SK1, contributed to the study design, data analysis, and interpretation and writing of first and subsequent drafts of the paper. TI, CW, RN, SK2, NG, ZW, RW,FN contributed to the data collection, laboratory analysis and data entry. FM, MM, RO, contributed to data analysis, interpretation, and editing the paper. GD, JC, SVP contributed to the design, data analysis, interpretation, and drafts of the paper. All authors read and approved the final manuscript.

\section{Funding}

Research reported in this publication was supported by the National Institute of Allergy and Infectious Diseases of the National Institutes of Health under Award Number R01Al099525 to S.K. and the Wellcome Trust. GD was supported by TyVac (Gates) and the Cambridge NIHR, BRC/AMR Theme.

\section{Availability of data and materials}

The datasets used and/or analyzed during the current study are available from the corresponding author on reasonable request.

\section{Ethics approval and consent to participate}

All procedures performed in studies involving human participants were in accordance with the ethical standards of the institutional and/or national research committee and with the 1964 Helsinki declaration, and its late amendments or comparable ethical standards. Ethical approval for this study was granted by the Scientific and Ethics Review Unit (SERU) of KEMRI (SSC No. 2076). Written informed consent was obtained from all parents/ guardians of minors included in the study.

\section{Consent for publication}

Not applicable.

\section{Competing interests}

The authors declare that they have no competing interests.

\section{Author details}

${ }^{1}$ Centre for Microbiology Research, Kenya Medical Research Institute, Off Mbagathi Road, PO Box 54840-00200, Nairobi, Kenya. ${ }^{2}$ Centre for Public Health Research, Kenya Medical Research Institute, Nairobi, Kenya. ${ }^{3}$ Department of Medicine, University of Cambridge, Cambridge, UK ${ }^{4}$ Department of Biomedical Sciences, Institute of Tropical Medicine, Antwerp, Belgium. ${ }^{5}$ Laboratory of Medical Microbiology, Vaccine \& Infectious Disease Institute, Universiteit Antwerpen, Antwerp, Belgium. ${ }^{6}$ International Centre for Diarrhoeal Disease Research, Dhaka, Bangladesh. 'Wellcome Sanger Institute, Wellcome Genome Campus, Hinxton, Cambridge, UK

Received: 14 February 2020 Accepted: 1 June 2020

Published online: 17 June 2020

\section{References}

1. Crump JA, Heyderman RS. A perspective on invasive Salmonella disease in Africa. Clin Infect Dis. 2015;61(Suppl 4):S235-40.

2. Uche IV, MacLennan CA, Saul A. A systematic review of the incidence, risk factors and case fatality rates of invasive nontyphoidal Salmonella (iNTS) disease in Africa (1966 to 2014). PLoS Negl Trop Dis. 2017;11(1):e0005118.
3. World Health Organization. Foodborne disease burden epidemiology reference group 2007-2015. In: WHO estimates of the global burden of foodborne diseases; 2015.

4. Feasey NA, Hadfield J, Keddy KH, Dallman TJ, Jacobs J, Deng X, et al. Distinct Salmonella Enteritidis lineages associated with enterocolitis in highincome settings and invasive disease in low-income settings. Nat Genet. 2016;48(10):1211-7.

5. Ao TT, Feasey NA, Gordon MA, Keddy KH, Angulo FJ, Crump JA. Global burden of invasive nontyphoidal Salmonella disease, 2010(1). Emerg Infect Dis. 2015;21(6):941-9.

6. Kariuki S, Mbae C, Onsare R, Kavai SM, Wairimu C, Ngetich R, et al. Multidrug-resistant nontyphoidal Salmonella hotspots as targets for vaccine use in management of infections in endemic settings. Clin Infect Dis. 2019; 68(Suppl 1):S10-5.

7. Feasey NA, Dougan G, Kingsley RA, Heyderman RS, Gordon MA. Invasive non-typhoidal Salmonella disease: an emerging and neglected tropical disease in Africa. Lancet (London, England). 2012;379(9835):2489-99.

8. Kariuki S, Onsare RS. Epidemiology and genomics of invasive nontyphoidal Salmonella infections in Kenya. Clin Infect Dis. 2015;61(Suppl 4):S317-24.

9. Maclennan CA. Out of Africa: links between invasive nontyphoidal Salmonella disease, typhoid fever, and malaria. Clin Infect Dis. 2014;58(5): 648-50.

10. Gordon MA, Graham SM, Walsh AL, Wilson L, Phiri A, Molyneux E, et al. Epidemics of invasive Salmonella enterica serovar enteritidis and S. enterica Serovar typhimurium infection associated with multidrug resistance among adults and children in Malawi. Clin Infect Dis. 2008;46(7):963-9.

11. Gordon MA. Salmonella infections in immunocompromised adults. J Inf Secur. 2008:56(6):413-22

12. Kingsley RA, Msefula CL, Thomson NR, Kariuki S, Holt KE, Gordon MA, et al. Epidemic multiple drug resistant Salmonella Typhimurium causing invasive disease in sub-Saharan Africa have a distinct genotype. Genome Res. 2009; 19(12):2279-87.

13. Kariuki S, Revathi G, Kariuki N, Kiiru J, Mwituria J, Muyodi J, et al. Invasive multidrug-resistant non-typhoidal Salmonella infections in Africa: zoonotic or anthroponotic transmission? J Med Microbiol. 2006;55(Pt 5):585-91.

14. Bachou H, Tylleskar T, Kaddu-Mulindwa DH, Tumwine JK. Bacteraemia among severely malnourished children infected and uninfected with the human immunodeficiency virus-1 in Kampala, Uganda. BMC Infect Dis. 2006; 6:160.

15. Ikumapayi UN, Antonio M, Sonne-Hansen J, Biney E, Enwere G, Okoko B, et al. Molecular epidemiology of community-acquired invasive nontyphoidal Salmonella among children aged 229 months in rural Gambia and discovery of a new serovar, Salmonella enterica Dingiri. J Med Microbiol. 2007:56(Pt 11):1479-84.

16. Vandenberg O, Nyarukweba DZ, Ndeba PM, Hendriksen RS, Barzilay EJ, Schirvel C, et al. Microbiologic and clinical features of Salmonella species isolated from bacteremic children in eastern Democratic Republic of Congo. Pediatr Infect Dis J. 2010;29(6):504-10

17. Hopewell MR, Graham JP. Trends in access to water supply and sanitation in 31 major sub-Saharan African cities: an analysis of DHS data from 2000 to 2012. BMC Public Health. 2014;14:208.

18. Park SE, Pham DT, Boinett C, Wong VK, Pak GD, Panzner U, et al. The phylogeography and incidence of multi-drug resistant typhoid fever in subSaharan Africa. Nat Commun. 2018;9(1):5094.

19. Khan MI, Ochiai RL, Soofi SB, Von-Seidlein L, Khan MJ, Sahito SM, et al. Risk factors associated with typhoid fever in children aged 2-16 years in Karachi, Pakistan. Epidemiol Infect. 2012;140(4):665-72.

20. Sur D, von Seidlein L, Manna B, Dutta S, Deb AK, Sarkar BL, et al. The malaria and typhoid fever burden in the slums of Kolkata, India: data from a prospective community-based study. Trans R Soc Trop Med Hyg. 2006; 100(8):725-33.

21. Ochiai RL, Acosta CJ, Danovaro-Holliday MC, Baiqing D, Bhattacharya SK, Agtini $M D$, et al. A study of typhoid fever in five Asian countries: disease burden and implications for controls. Bull World Health Organ. 2008;86(4):260-8.

22. Naheed A, Ram PK, Brooks WA, Hossain MA, Parsons MB, Talukder KA, et al. Burden of typhoid and paratyphoid fever in a densely populated urban community, Dhaka, Bangladesh. Int J Infect Dis. 2010;14(Suppl 3):e93-9.

23. Wong VK, Baker S, Pickard DJ, Parkhill JP, Feasey NA, Kingsley RA, et al. Phylogeographical analysis of the dominant multidrug-resistant $\mathrm{H} 58$ clade of Salmonella Typhi identifies inter- and intracontinental transmission events. Nat Genet. 2015;47(6):632-9. 
24. Holt KE, Baker S, Weill FX, Holmes EC, Kitchen A, Yu J, et al. Shigella sonnei genome sequencing and phylogenetic analysis indicate recent global dissemination from Europe. Nat Genet. 2012;44(9):1056-9.

25. Kariuki S, Revathi G, Kiiru J, Mengo DM, Mwituria J, Muyodi J, et al. Typhoid in Kenya is associated with a dominant multidrug-resistant Salmonella enterica serovar Typhi haplotype that is also widespread in Southeast Asia. J Clin Microbiol. 2010;48(6):2171-6.

26. Emary K, Moore CE, Chanpheaktra N, An KP, Chheng K, Sona S, et al. Enteric fever in Cambodian children is dominated by multidrug-resistant $\mathrm{H} 58$ Salmonella enterica serovar Typhi with intermediate susceptibility to ciprofloxacin. Trans R Soc Trop Med Hyg. 2012;106(12):718-24.

27. UN-Habitat. Global Reports on Human Settlements, Planning Sustainable Cities. 2009. https://unhabitat.org/planning-sustainable-cities-global-reporton-human-settlements-2009. HS Number 1192/09E, ISBN 978-18-4-407899-8.

28. Olack B, Feikin DR, Cosmas LO, Odero KO, Okoth GO, Montgomery JM, et al. Mortality trends observed in population-based surveillance of an urban slum settlement, Kibera, Kenya, 2007-2010. PLoS One. 2014;9(1):e85913.

29. Mutisya E, Yarime M. Understanding the grassroots dynamics of slums in Nairobi: the dilemma of Kibera informal settlements. ITJEMAST. 2011;2(2): 197-213.

30. Kyobutungi C, Ziraba AK, Ezeh A, Ye Y. The burden of disease profile of residents of Nairobi's slums: results from a demographic surveillance system. Popul Health Metrics. 2008;6:1.

31. Kenya National Bureau of Statistics: Kenya National Population and Housing Census. 2009. http://www.knbs.or.ke.

32. Mahabir R, Agouris P, Stefanidis A, Croitoru A, Crooks AT. Detecting and mapping slumsusing open data: a case study in Kenya. Intern J Digit Earth. 2020;13(6):683-707. https://doi.org/10.1080/17538947.2018.1554010.

33. Montana L, Lance PM, Mankoff C, Speizer IS, Guilkey D. Using satellite data to delineate slum and non-slum sample domains for an urban population survey in Uttar Pradesh, India. Spat Demogr. 2016;4(1):1-16.

34. Kuffer M, Pfeffer K, Sliuzas R. Slums from Space-15 Years of Slum Mapping Using Remote Sensing. Remote Sens. 2016;8(6):455.

35. Ehlayel MS, Bener A, Laban MA. Primary immunodeficiency diseases in children: 15 year experience in a tertiary care medical center in Qatar. J Clin Immunol. 2013;33(2):317-24.

36. Kucuk O, Bicer S, Ugras M, Col D, Giray T, Ciler Erdag G, et al. Report of data on children with non-typhi Salmonella gastroenteritis in a three-year period. Infez Med. 2016;24(3):194-200.

37. Dewan AM, Corner R, Hashizume M, Ongee ET. Typhoid fever and its association with environmental factors in the Dhaka metropolitan area of Bangladesh: a spatial and time-series approach. PLoS Negl Trop Dis. 2013; 7(1):e1998.

38. Shah SA, Suzuki H, Hassan MR, Saito R, Safian N, Idrus S. Spatial analysis of environmental factors influencing typhoid endemicity in Kelantan, Malaysia. Sains Malaysiana. 2012;41(7):911-9.

39. Akullian A, Ng'eno E, Matheson Al, Cosmas L, Macharia D, Fields B, et al. Environmental transmission of typhoid fever in an urban slum. PLoS Negl Trop Dis. 2015;9(12):e0004212.

40. Kariuki S, Revathi G, Gakuya F, Yamo V, Muyodi J, Hart CA. Lack of clonal relationship between non-typhi Salmonella strain types from humans and those isolated from animals living in close contact. FEMS Immunol Med Microbiol. 2002;33(3):165-71.

41. Jensen DA, Danyluk MD, Harris $L$, Schaffner DW. Quantifying the effect of hand wash duration, soap use, ground beef debris, and drying methods on the removal of Enterobacter aerogenes on hands. J Food Prot. 2015;78(4): 685-90.

42. Chlebicz A, Slizewska K. Campylobacteriosis, salmonellosis, yersiniosis, and listeriosis as zoonotic foodborne diseases: A review. Int J Environ Res Public Health. 2018;15(5):863.

43. Silva C, Calva E, Maloy S. One Health and food-borne disease: Salmonella transmission between humans, animals, and plants. Microbiol Spectr. 2014; 2(1):OH-0020-2013.

44. Zaidi MB, McDermott PF, Fedorka-Cray P, Leon V, Canche C, Hubert SK, et al Nontyphoidal Salmonella from human clinical cases, asymptomatic children, and raw retail meats in Yucatan, Mexico. Clin Infect Dis. 2006:42(1):21-8.

45. Breiman RF, Cosmas L, Njuguna H, Audi A, Olack B, Ochieng JB, et al. Population-based incidence of typhoid fever in an urban informal settlement and a rural area in Kenya: implications for typhoid vaccine use in Africa. PLoS One. 2012;7(1):e29119.
46. Ali M, Sur D, Kim DR, Kanungo S, Bhattacharya SK, Manna B, et al. Impact of Vi vaccination on spatial patterns of typhoid fever in the slums of Kolkata, India. Vaccine. 2011;29(48):9051-6.

47. Muti M, Gombe N, Tshimanga M, Takundwa L, Bangure D, Mungofa S, et al. Typhoid outbreak investigation in Dzivaresekwa, suburb of Harare City, Zimbabwe, 2011. Pan Afr Med J. 2014;18:309.

48. Vollaard AM, Ali S, van Asten HA, Widjaja S, Visser LG, Surjadi C, et al. Risk factors for typhoid and paratyphoid fever in Jakarta, Indonesia. Jama. 2004; 291(21):2607-15.

\section{Publisher's Note}

Springer Nature remains neutral with regard to jurisdictional claims in published maps and institutional affiliations.
Ready to submit your research? Choose BMC and benefit from:

- fast, convenient online submission

- thorough peer review by experienced researchers in your field

- rapid publication on acceptance

- support for research data, including large and complex data types

- gold Open Access which fosters wider collaboration and increased citations

- maximum visibility for your research: over $100 \mathrm{M}$ website views per year

At BMC, research is always in progress.

Learn more biomedcentral.com/submissions 